\title{
ASPECTOS TÉCNICOS E FUNCIONAIS DE DOIS ENGENHOS ALMANJARRA, IBIASSUCÊ, BAHIA
}

\section{TECHNICAL AND FUNCTIONAL ASPECTS OF TWO ALMANJARRA SUGARCANE MILLS FROM BAHIA, IBIASSUCÊ, BAHIA}

Marcellus d'Almeida de Almeida ${ }^{1}$ marcellus85@gmail.com/https://orcid.org/0000-0001-9369-3632

\section{RESUMO}

Neste trabalho temos como propósito lançar luz sobre aspectos técnicos e funcionais de engenhos almanjarra, comuns no Sertão nordestino. Para isto, foram apresentados dados primários sobre moenda e fornalha de dois engenhos do município de Ibiassucê na Bahia. Informações complementares sobre produção de rapadura e confecção de moenda foram colhidas em entrevistas com um proprietário de engenho e um artesão local.

Palavras-chave: Engenho almanjarra; Moenda de madeira; Rapadura.

\footnotetext{
${ }^{1}$ Autônomo.
} 


\begin{abstract}
In this paper we seek to shed light on some technical and functional aspects of sugarcane wooden mills (almanjarra type) in the countryside of eastern Brazil. To this end, we present primary data about the wooden mills and furnaces of two sugarcane mills complexes in Ibiassucê, Bahia. Complementary information about the production of rapadura and the construction of the mills were gathered through interviews with the sugarcane mill owner and a local artisan.
\end{abstract}

Keywords: Almanjarra Sugarcane mil; Wooden sugarcane mil; Rapadura.

\title{
ASPECTOS DESCRITIVOS ${ }^{2}$
}

O presente trabalho apresenta informações primárias sobre dois engenhos desativados no município de Ibiassucê, cujas moendas foram realizadas em madeira. Estas informações incorporam aspectos técnicos da confecção da moenda, a organização espacial das etapas de processamento da cana-de-açúcar até a rapadura, bem como descrições sobre todas as atividades desempenhadas por pessoas e animais.

Baseamo-nos em dados obtidos durante a escavação de um engenho na Fazenda Algodão, na visita ao engenho da Fazenda Vagem Queimada e em entrevistas com proprietários das fazendas, Santa Siliveira Guimarães e Antônio Oliveira, respectivamente, (Figura 1). Complementarmente, também entrevistamos Rosalino Joaquim Pinheiro, artesão que construiu e consertou moendas na região.

\footnotetext{
${ }^{2}$ Agradeço a Rosalino Pinheiro, Antônio Oliveira, Santa Siliveira e Homero Brito pelo acolhimento e informações sobre a confecção da moenda e funcionamento do engenho nas duas visitas a Ibiassucê.
} 


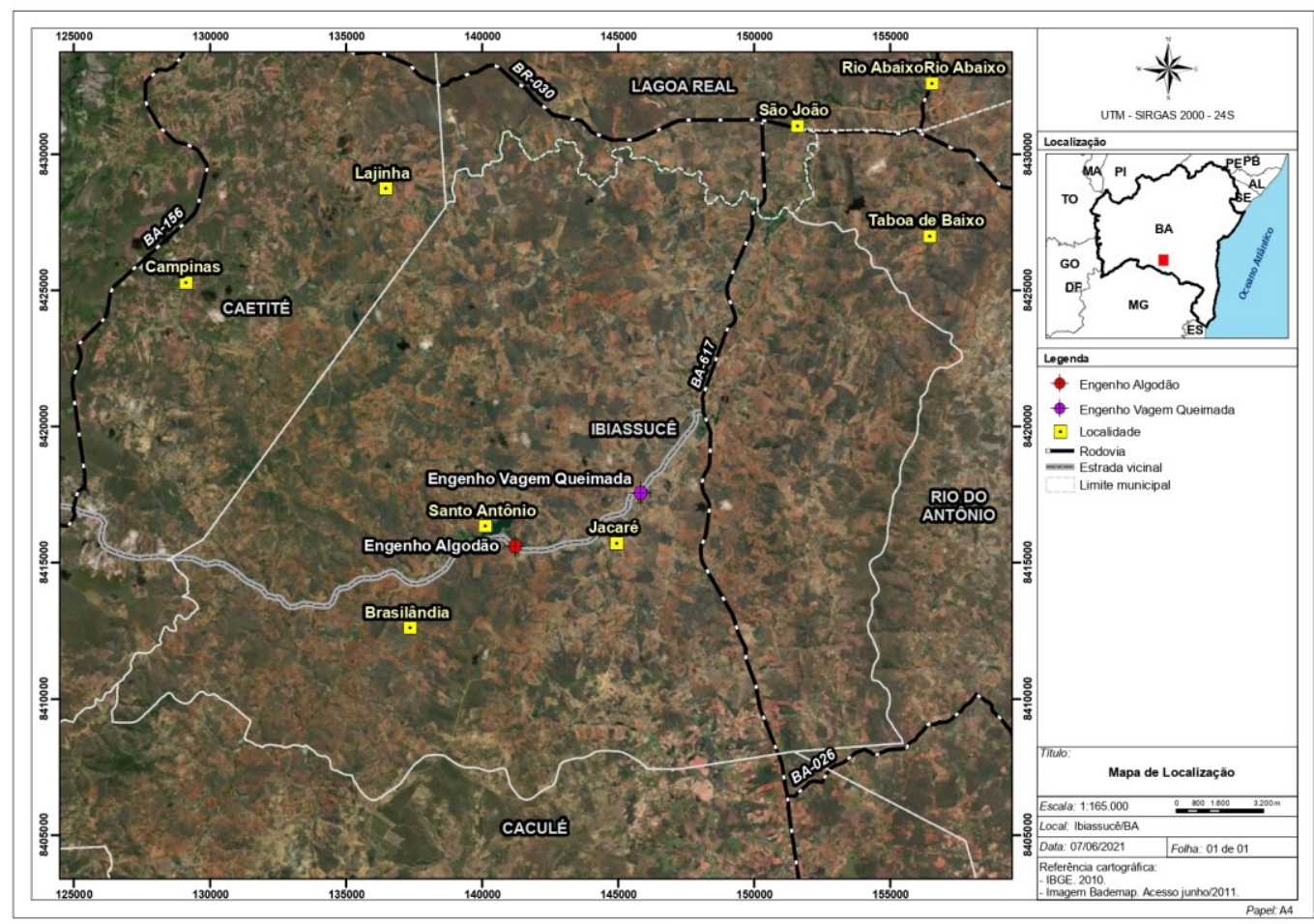

Figura 1: Localização dos engenhos visitados.

Grosso modo, o engenho do tipo almanjarra, assim denominado a partir da haste homônima que une o eixo principal aos animais, é dividido em duas partes, moenda e fornalha. A moenda é o local destinado ao esmagamento da cana-de-açúcar para a obtenção do sumo, escoado para um reservatório. O líquido é então levado para os tachos para ser peneirado concomitantemente à redução por evaporação, depois o xarope passa pela batedeira e finalmente é distribuído nas formas, etapas concentradas na fornalha. 


\section{Clio Arqueológica 2021, V36N1, p.141-169, ALMEIDA DOI: $10.51359 / 2448-2331.2021 .250749$}

Para a organização das descrições e comparações de produção, sobretudo da moenda, inspiramo-nos no conceito de cadeia operatória (LEROI-GOURHAN, 1964). Através da cadeia operatória é possível reconstituir a ordem e os parâmetros teórico-metodológicos envolvidos em cada estágio de realização de um ou vários objetos (GENESTE, 1991; INIZAN et al., 1995).

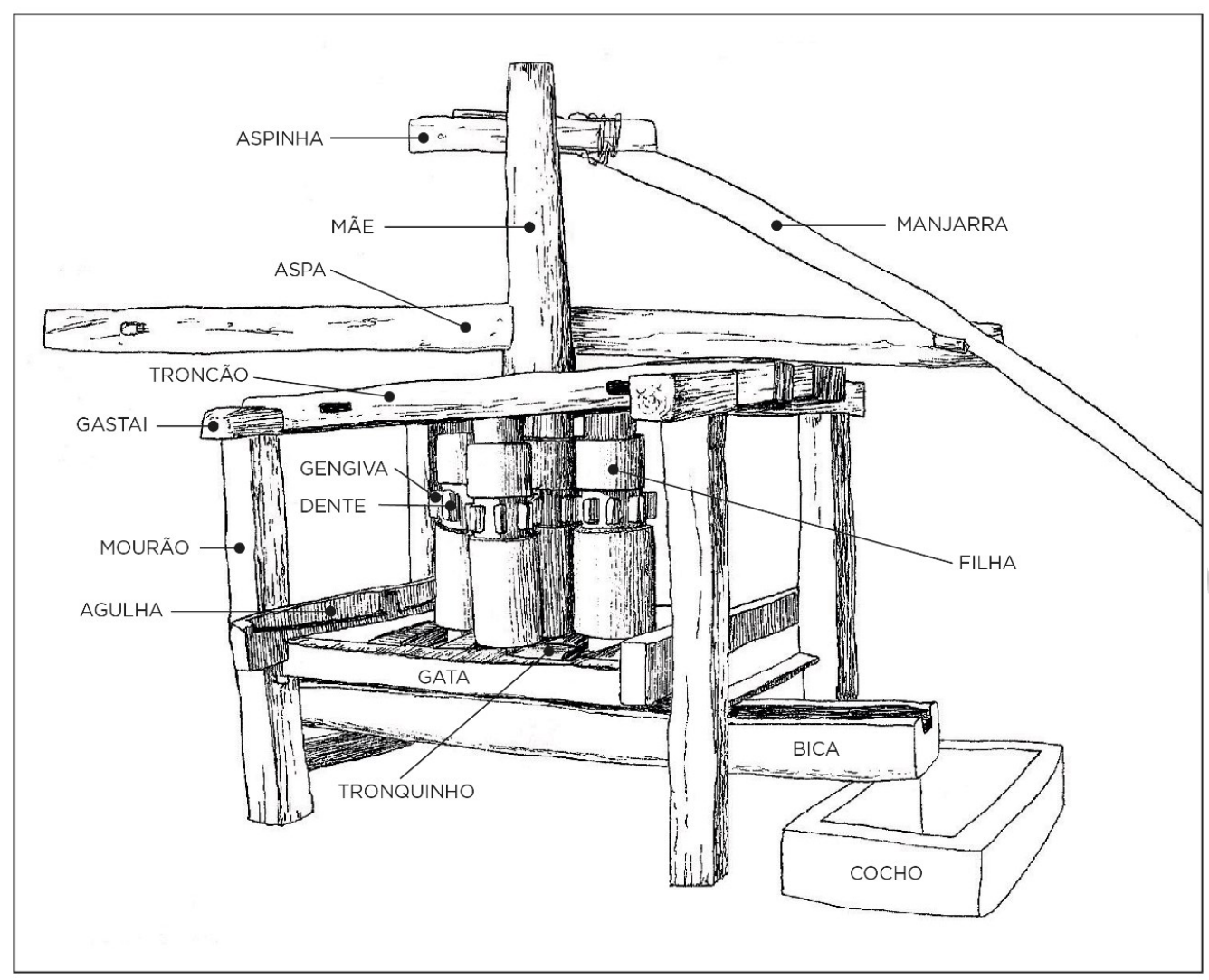

Figura 2. Peças da moenda. A tiradeira e as tábuas não estão presentes. Esta moenda pertence à Fazenda Vagem Queimada. 
A moenda de madeira é um mecanismo que depende de peças interligadas com funções específicas de sustentação, fixação e movimento. A estrutura incorpora 14 peças em madeira com fixação e imobilização atingidas principalmente por encaixes, todavia, existe o auxílio de pregos e arames. Fornecemos a seguir a descrição de cada parte da moenda e quantidades, (Figura 2):

a) Mourão: são quatro peças fincadas no solo, como postes, devendo ficar imóveis durante a atividade. Eles sustentam toda a estrutura da moenda;

b) Troncão: são duas peças, ambas na parte superior. Eles são fixados nos mourões no sentido do comprimento;

c) Tronquinho: somam oito, quatro na parte superior e quatro na parte inferior. Fixados aos troncões na parte superior e às gatas na parte inferior, os tronquinhos são os responsáveis pela manutenção da distância eficaz entre os eixos;

d) Gastai: são duas peças. Os gastais mantêm os troncões unidos aos mourões, na parte superior no sentido da largura;

e) Tábua: duas peças encaixadas sobre as agulhas. Possuem concavidades acordantes com a morfologia e localização dos eixos. As tábuas existem para conter os borbotões de sumo durante a passagem da cana-de-açúcar pelos eixos conduzindoo à bica logo abaixo;

f) Bica: uma única peça colocada na parte inferior da moenda. Nela todo o líquido deve cair e escorrer até o cocho;

g) Agulha: são duas peças perpendiculares às tábuas que as acomodam nos sulcos que possuem;

h) Mãe: é o eixo mais longo e mais importante da moenda. É através dela que todos os outros eixos secundários, ou "filhas", são movidos, recebendo energia da manjarra pelas aspas e aspinhas;

i) Filha: é o eixo secundário com quantidades variadas, desde duas peças até quatro. Em cada eixo, incluindo o principal, existem pequenas placas, denominadas de "dentes", em inserções na secção central de menor diâmetro, também chamada de gengiva. A outra secção de menor diâmetro, na extremidade apical dos eixos, chama-se "pescoço";

j) Aspa: peça que atravessa o eixo principal, as suas extremidades são presas às partes mediais das manjarras;

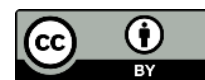


k) Aspinha: semelhante à aspa, esta peça também traspassa o eixo principal, porém entra em contato apenas com as extremidades das manjarras;

1) Manjarra ou monjarra: isolada ou em par, a manjarra possui uma extremidade presa à aspinha e a outra à tiradeira;

m) Tiradeira: esta peça é a intermediária entre a manjarra e a canga de bois.

Cada peça foi medida segundo as características morfológicas. Para as formas semelhantes a cubos e paralelogramos, auferimos comprimento, largura e espessura, enquanto que para as formas cilíndricas coletamos o comprimento e diâmetro. Medimos um exemplar de cada tipo de peça e escolhemos a secção média de cada um deles. Nos casos de peças com encaixes, tomamos medida da maior extensão. As ressalvas que fazemos concernem a morfologias variáveis e difíceis de serem enquadradas num ou noutro sólido geométrico, com vértices arredondados, talvez como medida de segurança ou por prescindir de uma forma determinada que não desempenharia qualquer melhoria em sua função.

\section{Dados arqueológicos do engenho da Fazenda Algodão}

As ruínas deste engenho estão distantes 30 metros da sede da fazenda composta por três edificações. O engenho foi construído em meados de 1950 e funcionou durante duas décadas para a produção exclusiva de rapadura. Dois artesãos foram citados como prováveis construtores da moenda, Otacílio Marques da Silva e Antônio Farias Primo. Nos engenhos da região, o reservatório para o sumo extraído da moenda, chamado de cocho ou cocheira, está próximo da moenda, fora dos limites da construção destinada ao processamento deste sumo até a transforma-lo em rapadura, denominada fornalha. Uma particularidade deste engenho é que a calha

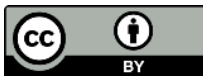


por onde escoa o sumo o conduz ao reservatório já no interior da fornalha através de um duto de madeira. Composto por duas metades adelgaçadas de um tronco, o duto possui 4,3 metros de comprimento e entre 20 e 15 centímetros de largura.

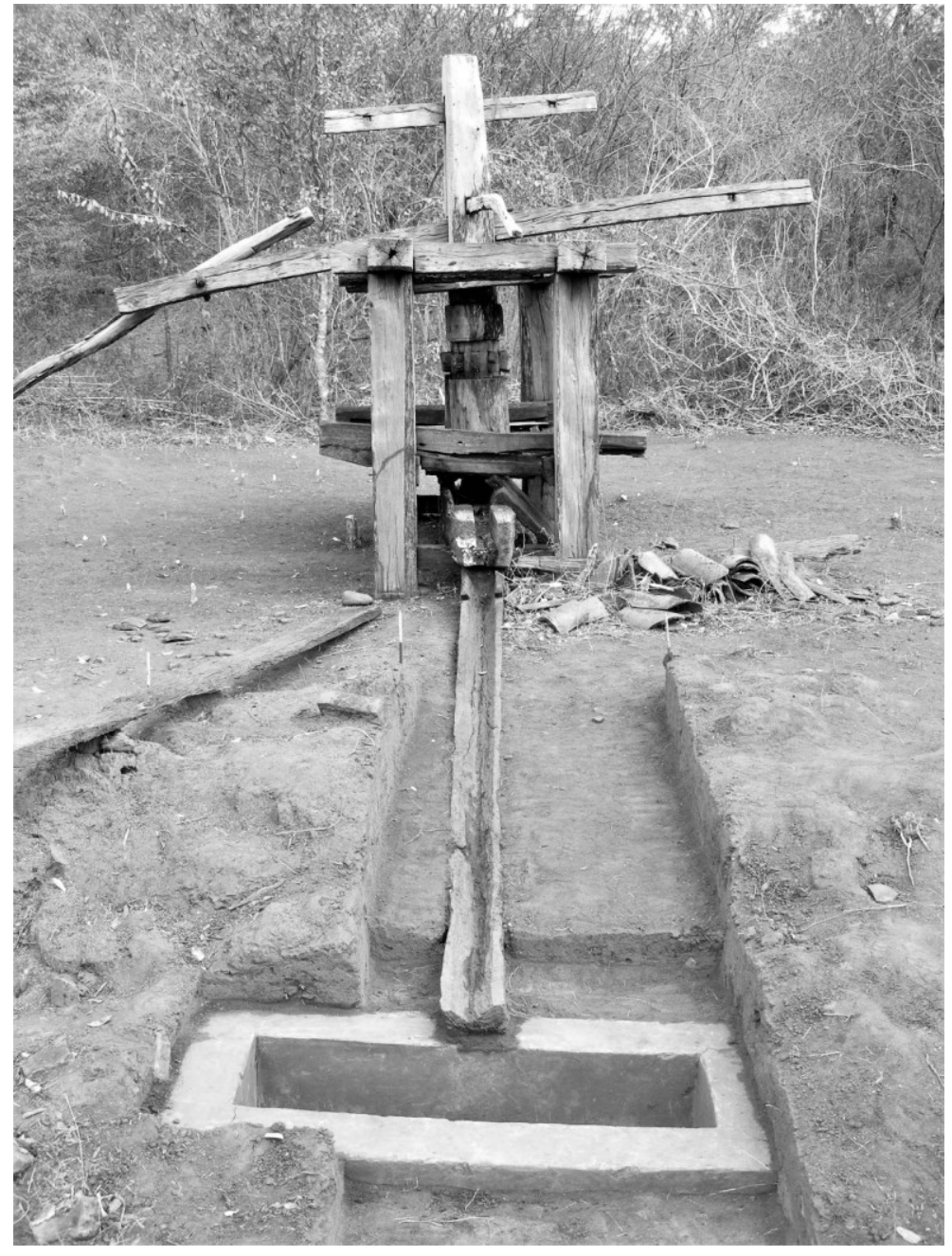

Figura 3. Interação moenda e fornalha através do duto na Fazenda Algodão. 
A metade superior do duto serviu para proteção do líquido pois seria traspassado pelos animais durante o funcionamento da moenda. É provável que tenha havido mais proteções e artifícios para imobilizar e selar o duto sejam com cordas ou arames, além do soterramento da canaleta como a escavação demonstrou (Figura 3). Um encaixe viabilizado a partir de dois entalhes na base na extremidade próxima à moenda e duas protuberâncias correspondentes na parte superior também foi notado.

\begin{tabular}{|c|c|c|c|c|}
\hline Peça & Comprimento & Largura & Espessura/Diâmetro & Material \\
\hline Mourão & 1,70 & 20 & 20 & Baraúna \\
\hline Troncão & 3,00 & 20 & 15 & Baraúna \\
\hline Gastai & 1,60 & 20 & 15 & Baraúna \\
\hline Bica & 3,00 & 40 & 25 & Baraúna \\
\hline Tronquinho & 1,60 & 22 & 15 & Baraúna \\
\hline Mãe & 2,60 & - & 36 & Baraúna \\
\hline Filha & 1,30 & - & 35 & Baraúna \\
\hline Agulha & 1,80 & 25 & - & Baraúna \\
\hline Tábua & - & - & 12 & Baraúna \\
\hline Gata & 2,20 & 28 & 10 & Baraúna \\
\hline Aspa & 4,30 & 15 & 8 & Baraúna \\
\hline Aspinha & 1,66 & 12 & 15 & Baraúna \\
\hline Manjarra & 4,30 & - & - & - \\
\hline Tiradeira & - & - & 12 & - \\
\hline
\end{tabular}

Tabela 1: Dimensões de um exemplar de cada tipo de peça da moenda da Fazenda Algodão. Medidas em centímetro. 
Embora não disponhamos de dados que apontem o pertencimento de várias peças a uma mesma árvore, já que apresentam graus variados de transformação, o fato de todas as peças da moenda serem de baraúna (Schinopsis brasiliensis) ensejaria a obtenção mais de uma peça por árvore. No entanto, as peças mais robustas como os mourões e troncões, a bica, o duto, e os eixos principal e secundários foram feitas apenas com o cerne e devem ter sido obtidas de árvores diferentes. Através dos comprimentos dos vértices representados pelos mourões, troncões e gastais, o volume da caixa da moenda é de $8,16 \mathrm{~m}^{3}$ (Tabela 1 ).

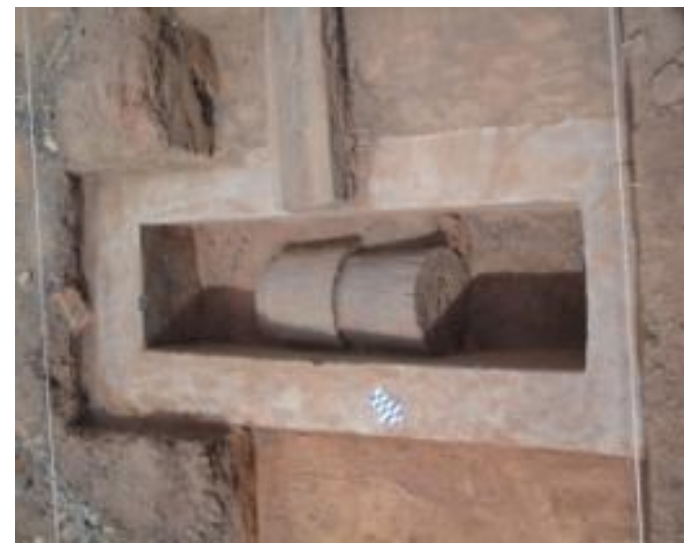

Figura 4: Parte do eixo secundário encontrado dentro do cocho.

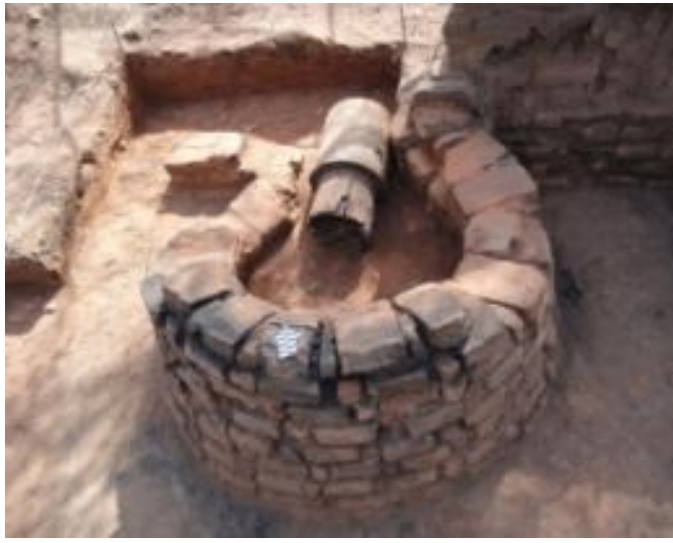

Figura 5: Parte do eixo secundário num dos fornos da Fazenda Algodão.

Descoberto pelas intervenções em subsuperfície, o cocho de cimento (160 x 68 x $55 \mathrm{~cm}$ ) está situado próximo aos limites externos da área de abrangência da fornalha. Nele foi identificado parte de um eixo secundário, serrado com precisão na altura da gengiva (Figura 4). 
A fornalha está situada numa cota mais baixa que aquela da moenda, cujo suave desnível é artificial. Apesar da ausência de elementos construtivos dispostos ao longo de todo o perímetro da fornalha, o montículo de sedimento criado em circunstância da desagregação dos tijolos de adobe, os dois lados incompletos com linhas de tijolos cozidos e o alinhamento do cocho, permitiram a projeção das dimensões da fornalha.

O perímetro desta estrutura é quadrangular com dois fornos numa das paredes de tijolos cozidos. Não foram notadas distinções cromáticas ou composicionais do sedimento que permitissem a delimitação precisa dos limites horizontais da estrutura.

Apesar de ter sido realizada limpeza e escavações superficiais no local da moenda, revelando principalmente a totalidade do duto, as intervenções em profundidade stricto sensu estiveram restritas à fornalha buscando evidenciar técnicas construtivas e perímetro. 


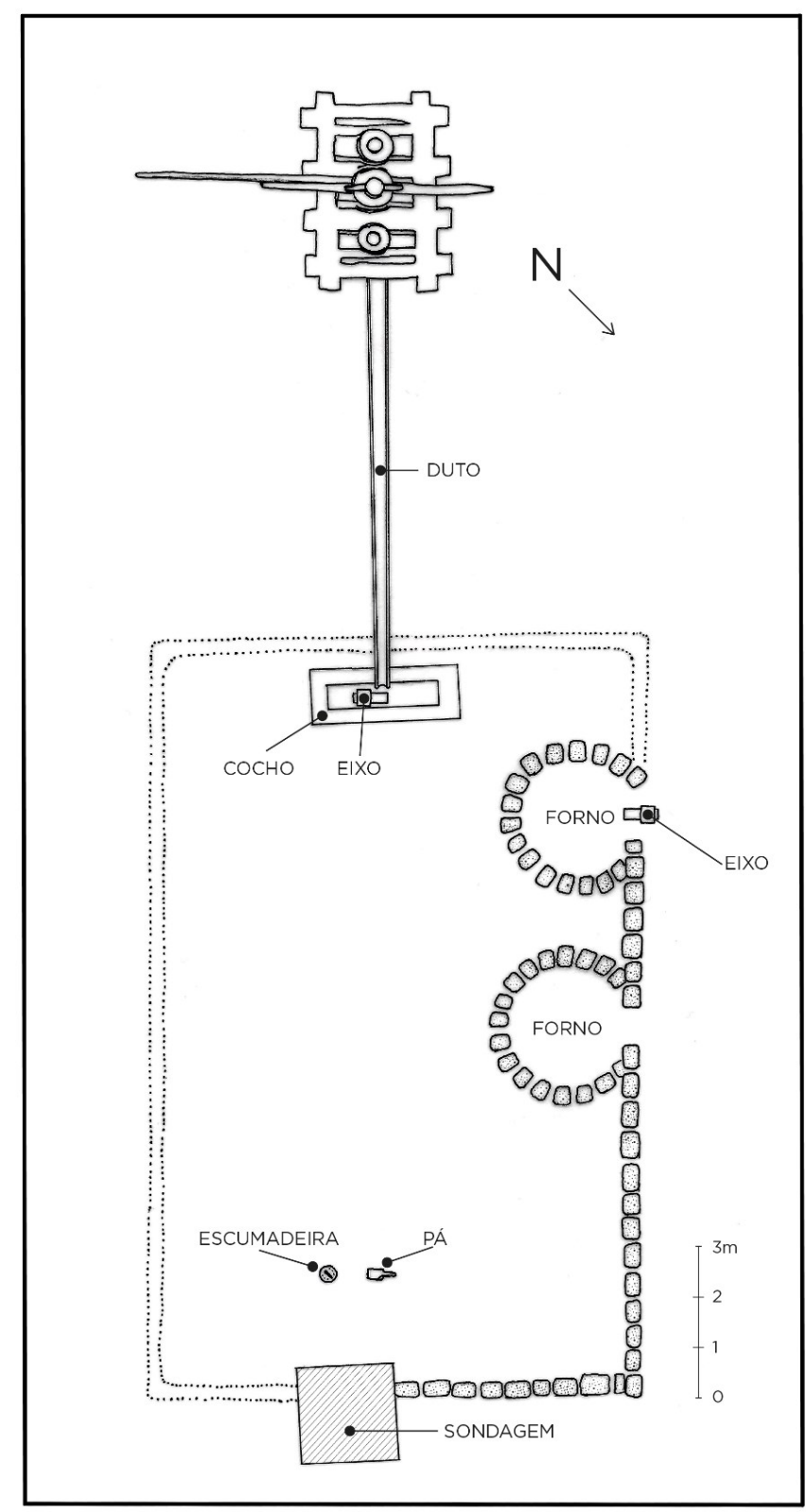

Figura 6. Planta baixa do engenho da Fazenda Algodão. Grande parte do duto, cocho, as duas partes do eixo, pá e escumadeira foram revelados depois da escavação. 


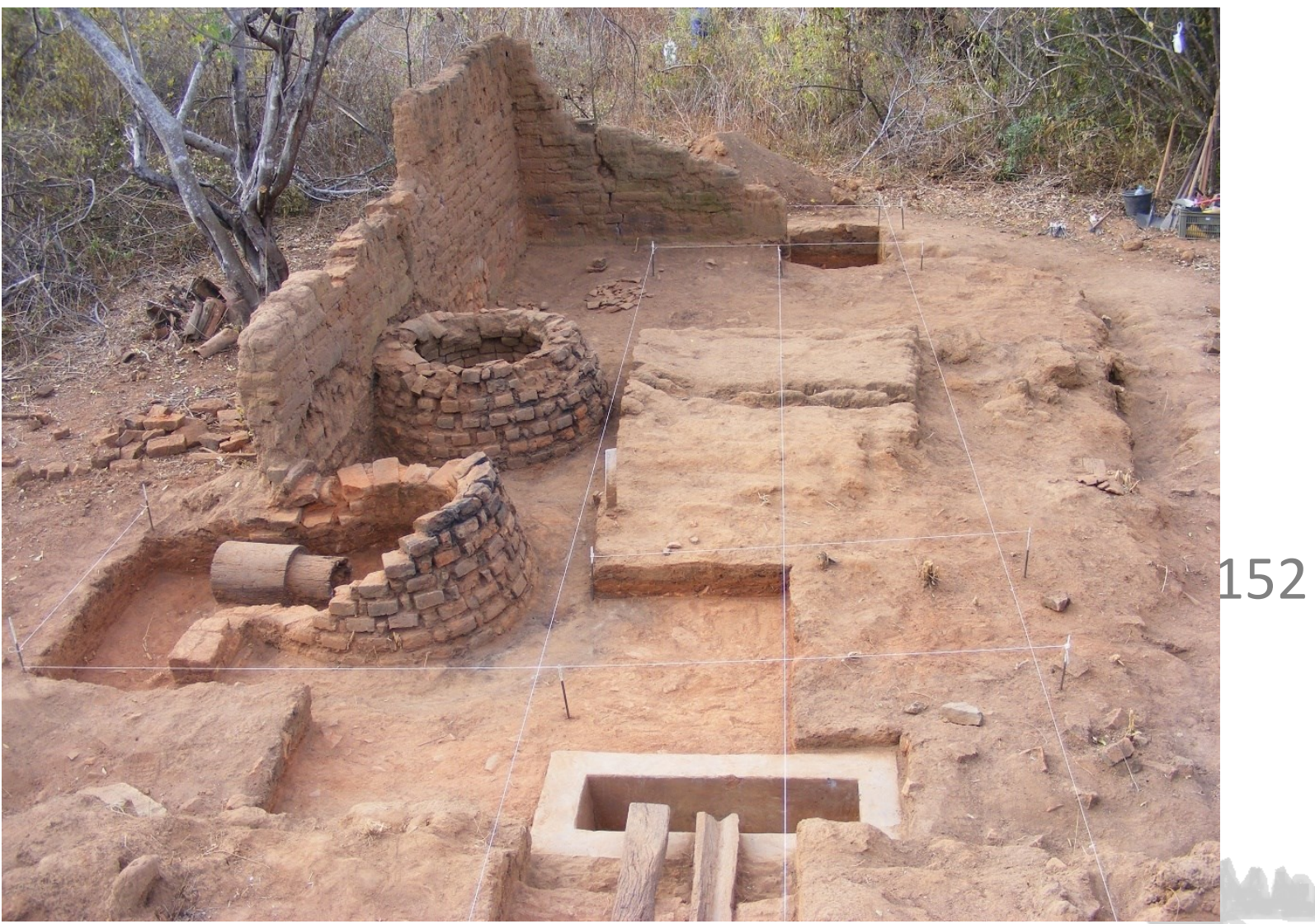

Figura 7. Escavação da fornalha vista a partir da moenda.

Os alicerces da fornalha, circunscritos às linhas de alvenaria, foram feitos de blocos rochosos a uma profundidade de cerca de 1 metro a partir da superfície do solo. Em seguida, iniciou-se a sequência de tijolos cozidos. Um fato curioso é que entre os alicerces e os tijolos foram dispostas cuidadosamente telhas inteiras, talvez com o propósito de regularizar a superfície sobre a qual começaria a sobreposição de

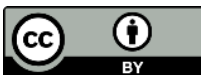




\section{Clio Arqueológica 2021, V36N1, p.141-169, ALMEIDA DOI: 10.51359/2448-2331.2021.250749}

tijolos cozidos. Do cinturão de alvenaria, com 50 centímetros de altura, 30 deles acima da superfície original do solo, foram erigidas paredes com tijolos crus, adobe. Os rejuntes dos dois tipos de tijolos foram de argila umedecida. Partes remanescentes das paredes erguidas ainda são visíveis (Figura 7).
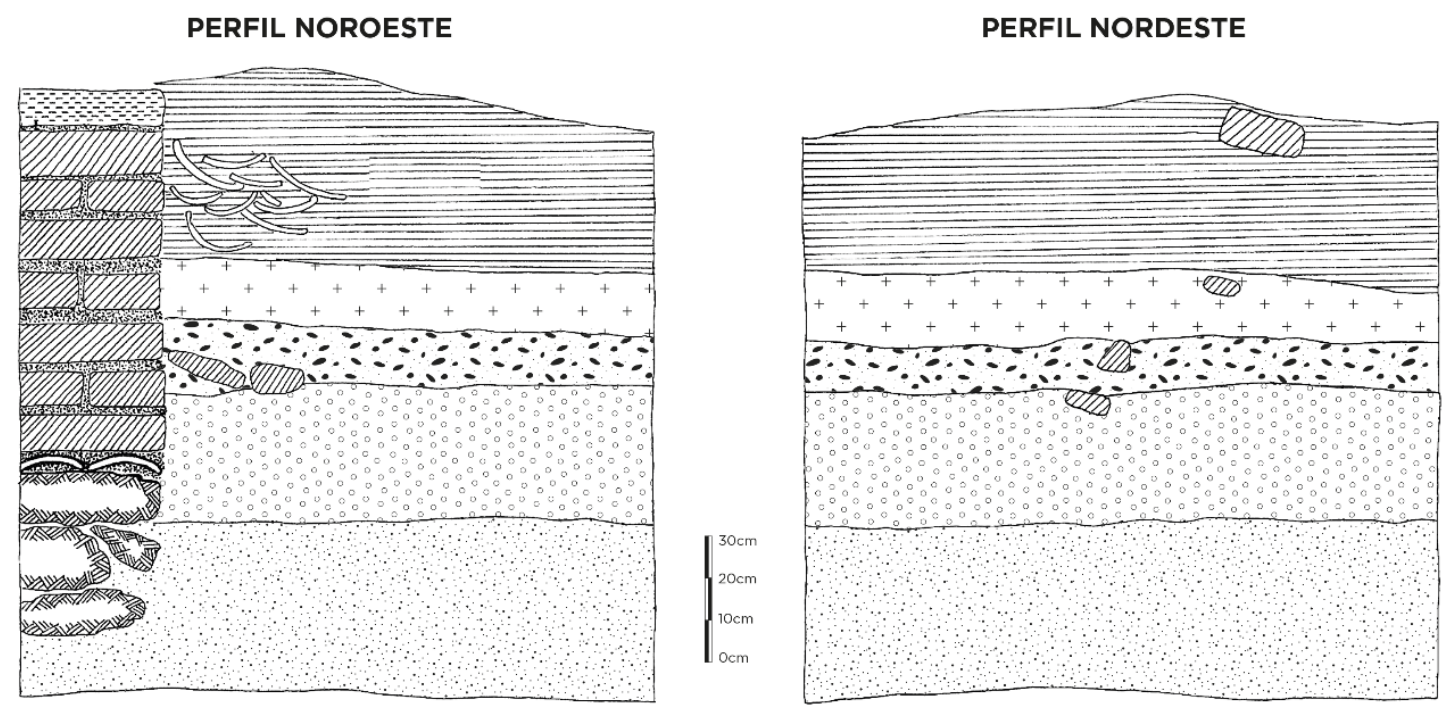

- SEDIMENTO ARENO-ARGILOSO CINZA AMARELADO (5YR 6/4) - SEDIMENTO ARGILOSO MARROM (5YR 6/8) - SEDIMENTO ARENO-ARGILOSO CINZA (7.5YR 6/6) - SEDIMENTO ARGILO-ARENOSO CINZA AVERMELHADO (5YR 6/4) - SEDIMENTO ARENO-ARGILOSO CINZA (5YR 6/3)

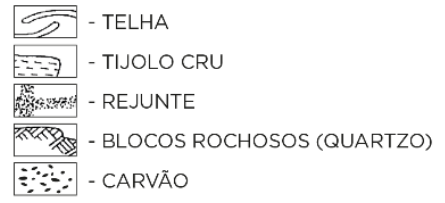

IIID - TIJOLO COZIDO

Figura 8. Perfis contíguos da sondagem escavada na fornalha. 


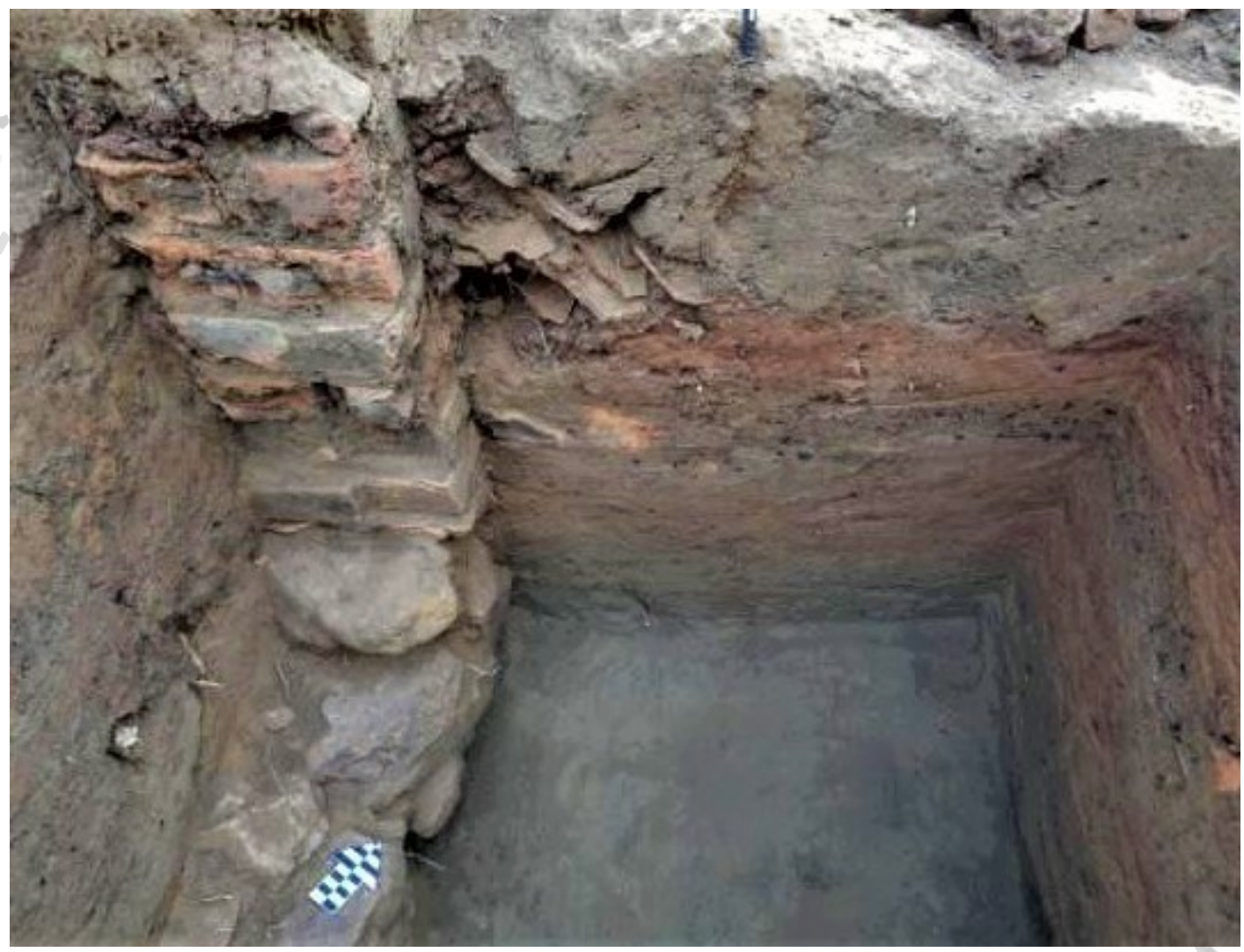

Figura 9. Fim da escavação da sondagem. Perfil noroeste.

Os tijolos de adobe desagregados formam uma espessa camada no interior da estrutura e fora dela constituindo a primeira camada identificada na Sondagem 1, (Figuras 8 e 9). A semelhança entre a primeira e a última sugere a utilização de sedimento argilo-arenoso local para a confecção de tijolos crus e dos rejuntes. Não foram notadas mudanças cromáticas e de composição dentre o sedimento que recobria o interior da estrutura e aquele utilizado na produção do adobe, ou seja, se

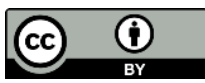


tratava de tijolos dissolvidos. Em alguns locais no interior da fornalha os montículos de adobe atingiram uma espessura de 30 centímetros. A escavação dos dois fornos, tangentes à parede noroeste, revelou que eram estruturas idênticas tanto do ponto de vista morfométrico quanto técnico.

A partir da base, esses fornos têm diâmetros de 1,5 metro e alturas de $60 \mathrm{~cm}$. A organização dos tijolos cozidos posicionava-os de tal modo a diminuir o espaço entre eles no interior do forno. Assim, o interstício entre os tijolos foi preenchido com fragmentos de tijolos e telha além do habitual rejunte argiloso. Nos limites superiores dos fornos, tijolos com marcas de desbastamento e fratura, bem como alguns fragmentos de telha tinham por finalidade acomodar e estabilizar os tachos de cobre. Em uma das estruturas de combustão foi identificado a outra parte do eixo encontrado dentro do cocho, como se selasse o orifício na parte externa da fornalha, pelo qual o forno era alimentado com lenha, (Figura 5).

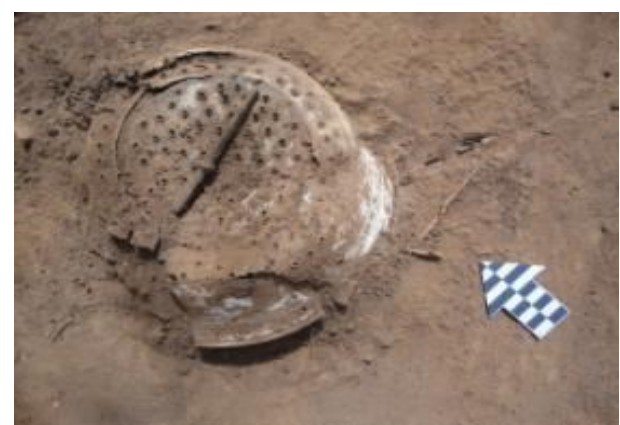

Figura 10: Parte da escumadeira e pino metálico identificados na escavação.

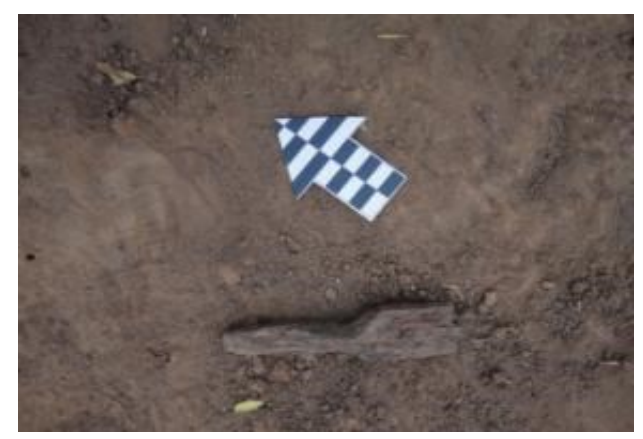

Figura 11: Parte da uma pá de madeira identificada na escavação. 
Partes de uma escumadeira e de uma pá foram encontradas a poucos centímetros de profundidade (Figuras 10 e 11). As peças resistentes da escumadeira que identificamos foram o recipiente reaproveitado e um pino, ambos metálicos, que seriam fixados a um fino cabo de madeira. $\mathrm{O}$ cabo não foi encontrado, talvez por ter sido pouco robusto e constituído de madeira leve. No entanto, a porção apical da pá esteve preservada, provavelmente graças ao tipo de madeira, mais resistente, e à maior espessura da peça.

\section{Engenho da Fazenda Vagem Queimada}

O engenho da Fazenda Vagem Queimada foi construído no ano de 1942 por Jacinto Fernandes por vontade de João Antônio de Oliveira, progenitor do atual proprietário da fazenda. Desde aquela data até o encerramento das atividades em 2009, o engenho, cujo foco principal era a rapadura, tivera uma produção marginal de cachaça nos primórdios de sua criação. A moenda teve eixos repostos e restaurados por Rosalino Pinheiro.

Situado na parte plana de uma elevação natural do terreno, o engenho encontra-se afastado das edificações residenciais da fazenda. A distância entre a moenda e a fornalha é de 15 metros. 


\section{Clio Arqueológica 2021, V36N1, p.141-169, ALMEIDA \\ DOI: 10.51359/2448-2331.2021.250749}

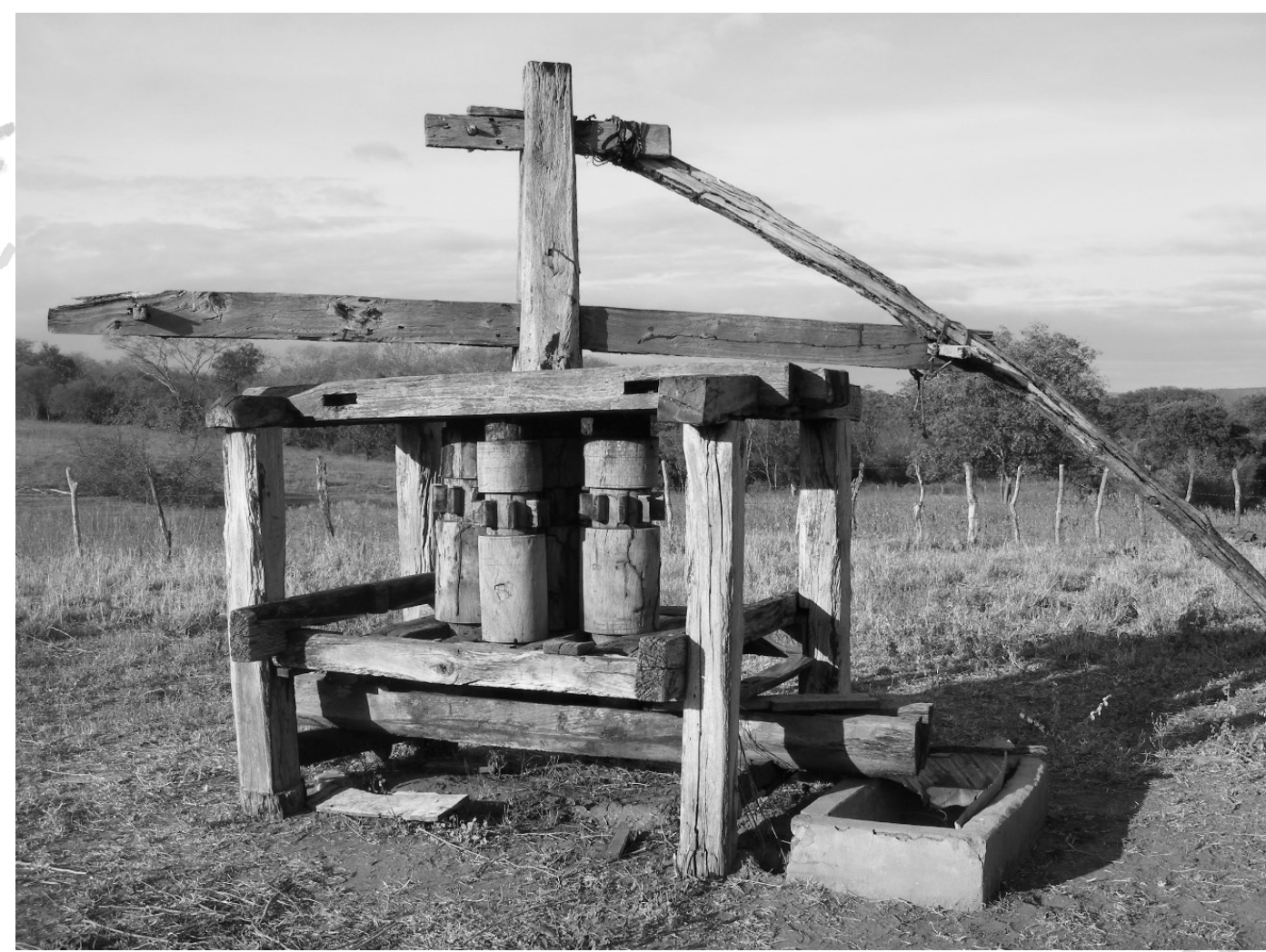

Figura 12. Moenda com quatro eixos secundários da Fazenda Vagem Queimada.

A moenda possui cinco eixos sendo quatro secundários. $O$ cocho $(140 \times 70 \times 63$ $\mathrm{cm}$ ) foi feito de cimento e está imediatamente após a bica, (Figura 12). 


\begin{tabular}{|c|c|c|c|c|}
\hline Peça & Comprimento & Largura & Espessura/Diâmetro & Material \\
\hline Mourão & 1,70 & 25 & 25 & Aroeira \\
\hline Troncão & 2,60 & 20 & 20 & Baraúna \\
\hline Gastai & 1,70 & 20 & 14 & Baraúna \\
\hline Bica & 3,10 & 50 & 30 & Baraúna \\
\hline Tronquinho & 1,10 & 20 & 15 & Baraúna \\
\hline Mãe & 2,80 & - & 35 & Baraúna \\
\hline Filha & 1,30 & - & 30 & Baraúna \\
\hline Agulha & 1,80 & 23 & 10 & Baraúna \\
\hline Tábua & 1,80 & 30 & 4 & Baraúna \\
\hline Gata & 1,93 & 23 & 15 & Baraúna \\
\hline Aspa & 4,00 & 20 & 13 & Baraúna \\
\hline Aspinha & 1,00 & 15 & 15 & - \\
\hline Manjarra & 5,00 & - & 12 & - \\
\hline Tiradeira & 2,50 & - & 7 & Fazenda \\
\hline
\end{tabular}

Tabela 2. Dimensões de um exemplar de cada tipo de peça da moenda da Fazenda Vagem Queimada. Medidas em centímetro.

A estrutura de moagem foi montada com peças de baraúna, salvo pelos mourões em aroeira (Tabela 2). Duas peças que transferem a energia da tração animal ao eixo principal, e o par de placas para conter o líquido almejado foram confeccionados em madeiras incógnitas. O volume da caixa desta moenda, tomando como referências o mourão, o troncão e o gastai, é de aproximadamente $7,51 \mathrm{~m}^{3}$. 


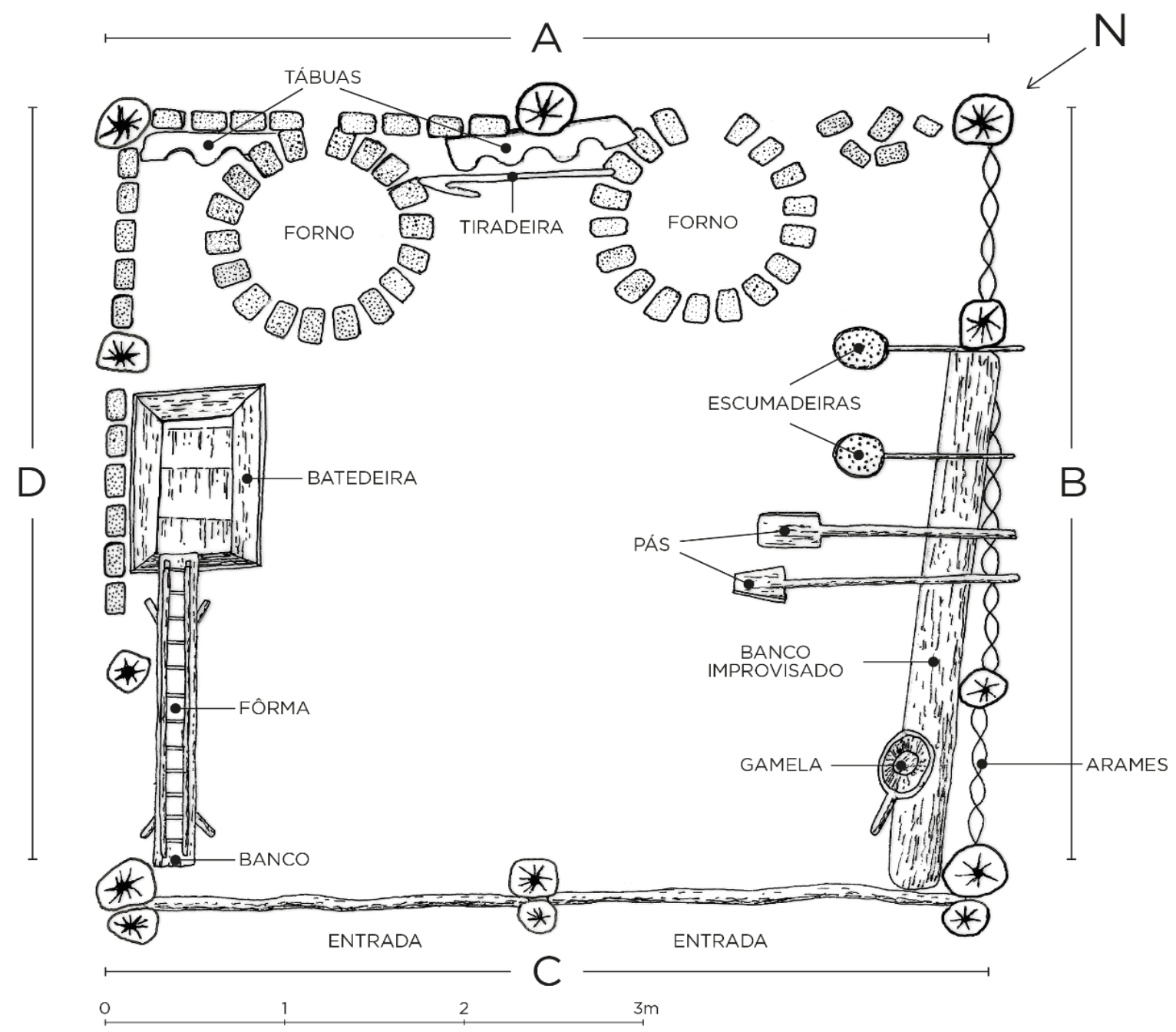

Figura 13. Planta baixa da fornalha do engenho Vagem Queimada com todos os utensílios e mobília utilizados para o processamento do caldo da cana-de-açúcar à modelagem da rapadura. As tábuas e tiradeira, peças pertencentes à moenda, foram encontradas na fornalha.

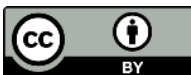


O perímetro da fornalha é um quadrado em que cada lado mede 4,7 metros. Sua estrutura consiste em dez pilares de madeira sobre o qual está assentado um telhado em duas águas, com vigas de madeira e telhas manuais. Os quatro lados são distintos uns dos outros em materiais construtivos e altura (Figura 13):

Lado A. É a meia parede de tijolos cozidos, incompleta em extensão, foi erguida até a altura dos dois fornos;

Lado B. Apenas arames separam a fornalha do exterior e um banco foi improvisado com apoios de dois troncos;

Lado C. Três sequencias de varas removíveis estão em cada metade desta secção. Trata-se da entrada da fornalha e está posicionada defronte à moenda;

Lado D. Dois terços desta parede são de tijolos cozidos enquanto que o ultimo terço, próximo à entrada da fornalha, é composto por estuque em varetas.

As bases dos fornos medem cerca de 1,3 metro de diâmetro com alturas de 1 metro, um pouco mais baixo que o nível do piso. Cada forno foi construído com tijolos e rejunte de argila, culminando com uma série de fragmentos de telha, às vezes sobrepostas.

Exceto os tachos de cobre, todos os tipos e quantidades de utensílios identificados neste lugar correspondem precisamente ao conjunto de objetos usados no momento da plena produção de rapadura antes de ser desativado o engenho, (Tabela 3). 


\begin{tabular}{|c|c|c|}
\hline Utensílio & Quantidade & Material \\
\hline Tacho & 2 & Cobre \\
\hline Escumadeira & 3 ou 4 & Alumínio e madeira (?) \\
\hline Gamela & 1 & Tamburi manso \\
\hline Batedeira & 1 & - \\
\hline Banco & 1 & Peroba \\
\hline Forma & 1 & Ipê \\
\hline Pá & 2 & - \\
\hline
\end{tabular}

Tabela 3. Quantidade e materiais dos utensílios da fornalha da fazenda Vagem Queimada.

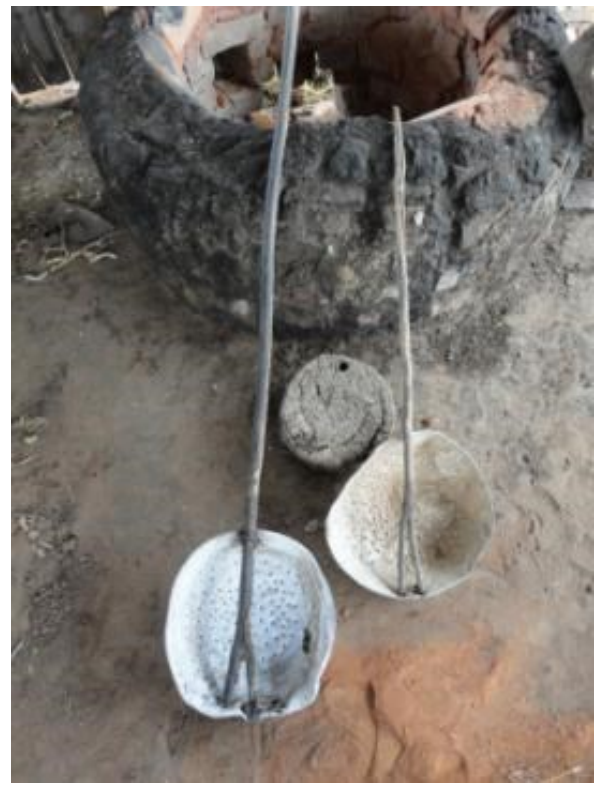

Figura 14. Forno e escumadeiras.

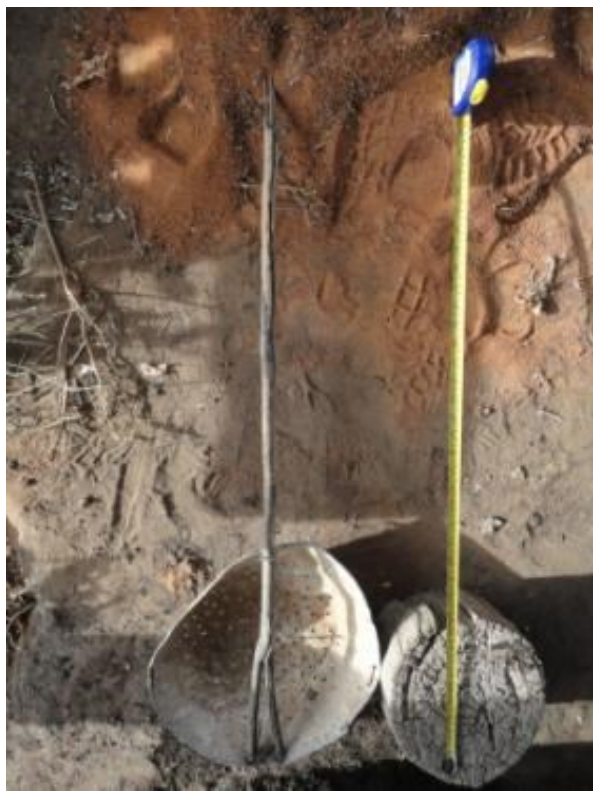

Figura 15. Uma das escumadeiras. 


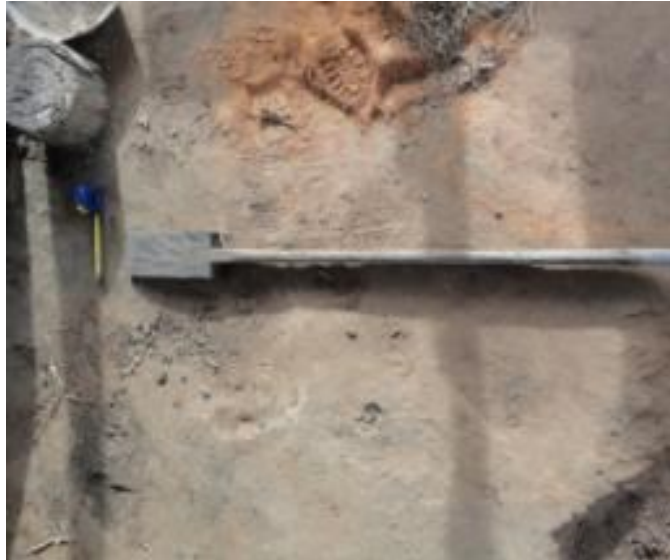

Figura 16. Pá de madeira com cabo cilíndrico.

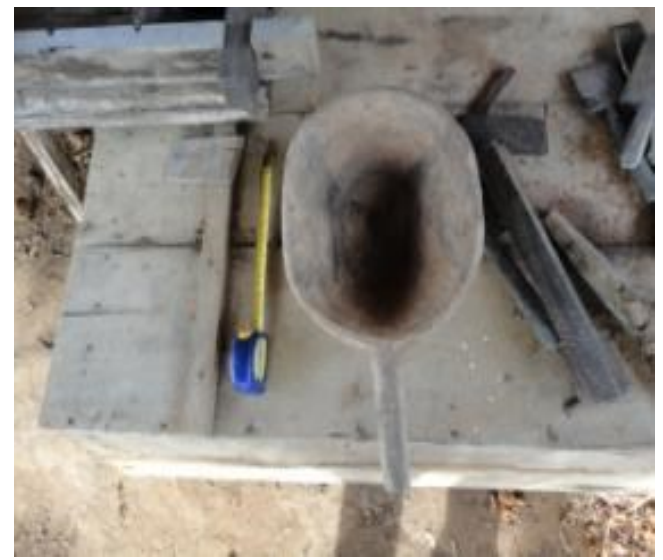

Figura 18. Gamela sobre a batedeira.

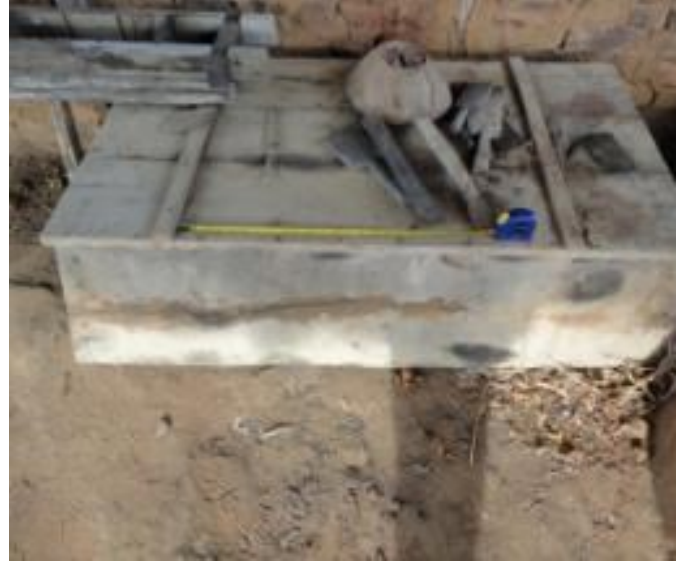

Figura 17: Batedeira de madeira.

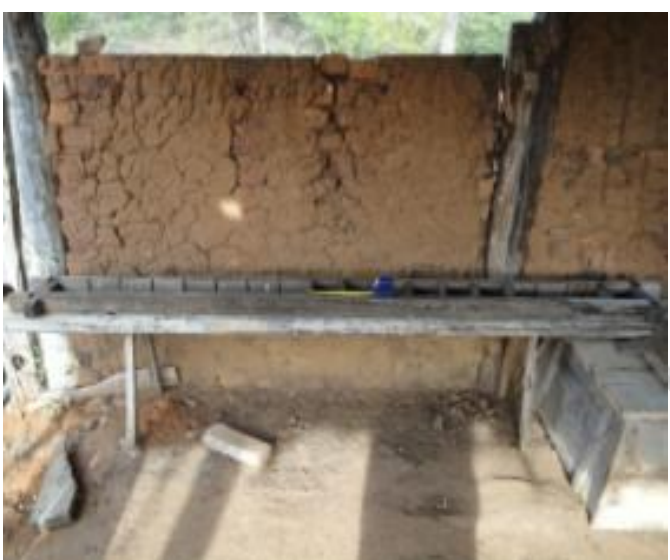

Figura 19. Forma de rapadura sobre o banco.

Os tachos e parte das escumadeiras são de metal, enquanto que o cabo da escumadeira e o restante dos objetos de madeira (Figuras 14, 15, 17 e 18). No

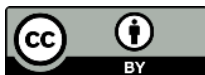


entanto, cada peça foi confeccionada a partir de uma madeira específica segundo a sua função. Madeira mais resistente e pesada foi destinada à confecção de pá e peças da fôrma, por exemplo, (Figuras 16 e 19).

\section{Construção da moenda}

O projeto da construção da moenda incorporava as seguintes noções, segundo o artesão Rosalino Joaquim Pinheiro:
a) localização da matéria-prima, concentrações de baraúnas;
b) onde o processo da confecção das peças iria se desenvolver;
c) distância entre o local de transformação das peças e a área do engenho;
d) tempo de realização e transporte das peças; e) montagem da moenda e ajustes.

Antes da localização e transformação da matéria prima, o proprietário decidia o tipo de moenda que desejava. A quantidade de eixos secundários determina o tamanho da moenda. A moenda com dois eixos era chamada de "Engenho Menor" e com quatro eixos "Engenho Maior", mas a caixa da moenda de ambas era praticamente a mesma.

A matéria prima lenhosa era obtida na região, preferencialmente nas áreas circunvizinhas aos locais onde seriam construídos os engenhos. A baraúna é a madeira usada em todas as peças da moenda, das manjarras até os mourões. A aroeira (Schinus terebinthifolia) eventualmente substituía a baraúna nos mourões, 
no entanto, por ser demasiado rija e fibrosa para suportar movimento e flexões era, portanto, inapta para a função desenvolvida pelas demais peças.

Após a derrubada da árvore, o artesão deveria trabalhar a madeira ainda fresca aproveitando a menor resistência ao corte. Almejava-se o cerne da árvore por causa de sua solidez e homogeneidade. Os utensílios usados pelo artesão eram o serrote, machado, formão, enxó, marreta de madeira e compasso.

A confecção dos eixos primário e secundários tinham um tratamento diferente, com maior número de gestos técnicos dispendidos. O eixo ainda amorfo mesmo depois de desbastado era firmado em dois grandes parafusos, um em cada extremidade. Com o auxílio de pessoas para girar o bloco cilíndrico sobre o próprio eixo, o artesão esculpia-o com o formão.

Para o funcionamento da moenda, os ajustes entre os eixos eram fundamentais. Apesar de serem tolerados pequenas diferenças nas medidas de espessura, se a diferença ultrapassasse $5 \mathrm{~cm}$, o eixo deveria ser abandonado, e outro deveria ser feito. Quando o objetivo era uma moenda de quatro eixos, três possuíam medidas idênticas e um seria um pouco menor. No entanto, o que deveria primar era a proporção entre os eixos, implicando numa sútil oscilação $(<5 \mathrm{~cm})$ entre as dimensões dos eixos tanto para transferência de energia como para eficácia durante a moagem. 


\begin{tabular}{|c|c|c|}
\hline Peça & Quantidade & Tempo de realização \\
\hline Mourão & 1 & 1 dia \\
\hline Gastai & 2 & 1 dia \\
\hline Gata & 2 & 1 dia \\
\hline Mãe & 1 & 3 dias \\
\hline Filha & 1 & 2 dias \\
\hline
\end{tabular}

Tabela 4: Tipos de peça pelo tempo de realização.

Antes do advento e popularização da motosserra, com os utensílios supramencionados, o tempo estimado desde a obtenção da matéria-prima e confecção de todas as peças da moenda era de uma quinzena. Os eixos são as peças que mais demandam tempo de realização devido às quantidades e precisão de gestos, regularização de todas as superfícies, verificação de simetrias e proporções, por exemplo (Tabela 4). Depois do transporte ao local determinado e montagem da moenda, costumeiramente era deixado uma quantidade excedente de dentes para reposição imediata por qualquer indivíduo da fazenda, sem a necessidade da presença do artesão.

\section{Comparação entre os engenhos}

As diferenças entre os dois engenhos puderam ser notadas tanto na moenda quanto na fornalha, porém, foi a adição de um elemento no Engenho Algodão que demarca a interação entre aquelas duas áreas de atividade. O duto que conjugava a bica da moenda ao cocho já no interior da fornalha, dispensando o transporte humano, implicou na análise topográfica do terreno para a escolha da construção de 
montagem das estruturas, além de intervenções no solo. Essas retiradas de sedimento tiveram o objetivo de acomodar as duas partes do duto.

No que concerne à estrutura da moenda, a distinção entre os chamados "Engenho grande" e o "Engenho pequeno", que na verdade se referem a moendas segundo as quantidades de eixos secundários, prevê a igualmente a quantidade de indivíduos requeridos para a atividade de moagem. Para a moenda do engenho Algodão, com dois eixos, houve a necessidade de dois indivíduos pois um deles seria responsável por introduzir a cana-de-açúcar e o outro por pegá-la do outro lado, empilhá-la para passar novamente a fim de extrair o máximo de sumo. Na moenda da Fazenda Vagem Queimada, os quatro eixos mobilizavam as hastes de cana-de-açúcar para o mesmo lado em que foram colocadas, então apenas um indivíduo seria capaz de conduzir a atividade. Esperava-se que as dimensões volumétricas das caixas fossem proporcionais à quantidade de eixos secundários, todavia isto não foi verificado. $\mathrm{O}$ “engenho grande" da fazenda Vagem Queimada tem volume menor que o "engenho pequeno" da fazenda Algodão, porém a diferença de $0,65 \mathrm{~m}^{3}$ pode ser desprezível para impedir a introdução ou retirada de eixos secundários.

A variação das dimensões foi observada praticamente em todas as peças das moendas, salvo nas tábuas e tiradeira, ausentes na Fazenda Algodão. No entanto, as disparidades mais importantes, superiores a 30 centímetros, são notadas no comprimento de peças que não desempenham papéis dinâmicos no mecanismo das moendas. Entre os eixos a variação foi igual ou inferior a 20 centímetros. 
A carência de medidas de cada uma das peças parece não ser o problema fundamental na tentativa de traçar paralelos entre as duas moendas, já que as peças cuja função não era subordinada à forma tiveram um acabamento irregular ou assimétrico, com espessuras diferentes ao longo do comprimento, abaulamento ou criação de faces nos vértices e arestas, e assim por diante. A recepção e transferência de energia impunham aos eixos posições e morfologias específicas criando uma sinergia entre todas as peças da máquina tanto quanto entre estas peças e os indivíduos e animais. Logo, cada uma das moendas deve ser considerada una, que apesar de similaridades morfométricas, elas excedem os limites definidos pelo artesão para os eixos da estrutura.

Sobre as fornalhas pode-se dizer que as semelhanças vão desde aspectos construtivos até utensílios usados para o processamento do sumo e obtenção das rapaduras. O perímetro de ambas possui dois lados contíguos com paredes de tijolos cozidos e crus, enquanto que os outros dois estiveram provavelmente limitados a usos de varas de madeira e arames. Com isso, as construções, com telhas sustentadas por pilares e vigas de madeira, garantiriam o arejamento necessário para o local onde seria queimada a lenha e seriam exalados os vapores da garapa durante cerca de 20 horas por dia.

Resquícios de pá e escumadeira foram encontrados na área escavada da fornalha do engenho Algodão, que foram utensílios encontrados íntegros na fazenda Vagem Queimada. Muitos objetos da fornalha foram reaproveitados e reutilizados, dos 
quais podemos citar bancos, formas, batedeira, pás e gamelas, e por fim os tachos, mais valiosos, ausentes nas duas fornalhas.

\section{CONSIDERAÇÕES FINAIS}

O que foi apresentado neste trabalho não tem a pretensão de posicionar os dois engenhos num quadro evolutivo, nem discorrer em minúcias sobre aspectos construtivos das estruturas, mas revelar algumas etapas da confecção da moenda e disposição da tralha usada na fornalha.

Demonstrou-se através da escavação do engenho Algodão que existem semelhanças com o engenho Vagem Queimada, embora desativado há quase uma década, nele foram mantidos os itens para o pleno desenvolvimento da produção da rapadura. Tais congruências foram identificadas na máquina de moer a cana-de-açúcar em virtude das características morfológicas e nas dimensões das peças que a constituem, com a condição de que essas máquinas sejam consideradas como uma unidade complexa de interação entre peças e animais.

As moendas revelaram imposições que começam com o tipo de matéria-prima e morfologia de cada uma das peças, mas também são identificadas na relação espacial e na transferência de energia entre as peças. Para a apreensão adequada dessas interações é necessário um maior número de exemplares, bem como uma maior quantidade de medidas aferidas em cada peça. 


\section{REFERÊNCIAS BIBLIOGRÁFICAS}

GENESTE, J.-M. Systèmes techniques de production lithique: variations technoéconomiques dans les processus de realization des outillages paléolithiques. Techniques et culture 17-18: 1-35, 1991.

INIZAN, M.-L., REDURON-BALLINGER, H. ROCHE e J. TIXIER. Préhistoire de la Pierre Taillée - T. 4: Technologie de la pierre taillée. CREP, Meudon, 1995.

LEROI-GOURHAN, A. Le geste et la parole. 1. Techniques et langage. Paris: Albin Michel, 1964. 